\title{
Quantifying the impact of solid-phase extraction on chromophoric dissolved organic matter composition
}

Wünsch, Urban J.; Geuer, Jana K.; Lechtenfeld, Oliver J.; Koch, Boris P.; Murphy, Kathleen R.; Stedmon, Colin A.

Published in:

Marine Chemistry

Link to article, DOI:

10.1016/j.marchem.2018.08.010

Publication date:

2018

Document Version

Peer reviewed version

Link back to DTU Orbit

Citation (APA):

Wünsch, U. J., Geuer, J. K., Lechtenfeld, O. J., Koch, B. P., Murphy, K. R., \& Stedmon, C. A. (2018).

Quantifying the impact of solid-phase extraction on chromophoric dissolved organic matter composition. Marine Chemistry, 207, 33-41. https://doi.org/10.1016/j.marchem.2018.08.010

\section{General rights}

Copyright and moral rights for the publications made accessible in the public portal are retained by the authors and/or other copyright owners and it is a condition of accessing publications that users recognise and abide by the legal requirements associated with these rights.

- Users may download and print one copy of any publication from the public portal for the purpose of private study or research.

- You may not further distribute the material or use it for any profit-making activity or commercial gain

- You may freely distribute the URL identifying the publication in the public portal 


\section{Accepted Manuscript}

Quantifying the impact of solid-phase extraction on chromophoric dissolved organic matter composition

Urban J. Wünsch, Jana K. Geuer, Oliver J. Lechtenfeld, Boris P. Koch, Kathleen R. Murphy, Colin A. Stedmon

PII: S0304-4203(18)30125-7

DOI: doi:10.1016/j.marchem.2018.08.010

Reference: MARCHE 3588

To appear in: Marine Chemistry

Received date: 14 May 2018

Revised date: 30 August 2018

Accepted date: 31 August 2018

Please cite this article as: Urban J. Wünsch, Jana K. Geuer, Oliver J. Lechtenfeld, Boris P. Koch, Kathleen R. Murphy, Colin A. Stedmon, Quantifying the impact of solidphase extraction on chromophoric dissolved organic matter composition. Marche (2018), doi:10.1016/j.marchem.2018.08.010

This is a PDF file of an unedited manuscript that has been accepted for publication. As a service to our customers we are providing this early version of the manuscript. The manuscript will undergo copyediting, typesetting, and review of the resulting proof before it is published in its final form. Please note that during the production process errors may be discovered which could affect the content, and all legal disclaimers that apply to the journal pertain. 


\section{Quantifying the impact of solid-phase extraction on chromophoric dissolved organic matter composition}

Urban J. Wünsch ${ }^{1,2}$, Jana K. Geuer ${ }^{3}$, Oliver J. Lechtenfeld ${ }^{4}$, Boris P. Koch ${ }^{3}$, Kathleen R. Murphy ${ }^{2}$ Colin A. Stedmon $^{1}$

${ }^{1}$ Chalmers University of Technology, Architecture and Civil Engineering, Water Environment Technology, Sven Hultins Gata 6, 41296 Gothenburg, Sweden

${ }^{2}$ National Institute of Aquatic Resources, Technical University of Denmark, Kemitorvet, Kgs. Lyngby 2800, Denmark

3 Alfred Wegener Institute Helmholtz Centre for Polar and Marine Research, Am Handelshafen 12, 27570 Bremerhaven

${ }^{4}$ Department of Analytical Chemistry, Helmholtz Centre for Environmental Research - UFZ, Permoserstrasse 15, 04318 Leipzig, Germany

Correspondence to: Urban J. Wünsch (wuensch@chalmers.se), Present address: Chalmers University of Technology, Sven Hultins Gata 6, 41296 Gothenburg, Sweden.

Running head: Impact of DOM extraction on optical properties 


\begin{abstract}
Advancing our understanding of the behaviour of dissolved organic matter (DOM) in aquatic environments necessitates efforts to combine complementary analytical data sets. However, some analytical measurements require sample pre-treatment, while others are carried out on bulk water samples, and it remains unclear if the resulting data sets can be compared. Here, we investigated the impact of solid-phase extraction with PPL resins on DOM optical properties. In samples from contrasting Arctic fjords, extraction efficiencies based on optical properties varied spectrally with averages between $31 \pm 13 \%$ at $411 \mathrm{~nm}$ and $40 \pm 12 \%$ at $363 \mathrm{~nm}$ for chromophoric DOM. Similarly, the extraction efficiency for specific fluorescence components varied between $37 \pm 16 \%$ and $58 \pm 18 \%$. Solid-phase extraction also decreased $\mathrm{S}_{275-295}$, fluorescence index, and the freshness index, but increased $S_{350400}$, and apparent fluorescence quantum yields, indicating that the extraction process was qualitatively selective. Six fluorescence components identified independently for bulk water and extracted DOM data using parallel factor analysis exhibited different behaviours. Three had identical spectral properties before and after extraction, although their extraction efficiencies varied with water mass characteristics and DOM composition, whereas three other components appeared to change after extraction. With the exception of one fluorescence component, the dynamics of optical properties in bulk water samples were not accurately reflected by DOM extracts. These results indicate that solid-phase extraction imparts a qualitative selectivity that leads to the homogenization of DOM extracts relative to the ir original samples. Efforts to integrate chemical information from different analytical methods should prioritize comparisons of measurements obtained on the same samples.
\end{abstract}

Keywords: CDOM; FDOM; PPL; fluorescence spectroscopy; PARAFAC; Arctic 


\section{Introduction}

The biogeochemistry of dissolved organic matter (DOM) and its chemical characterization has been the focus of much research in past decades due to its important role as a carbon and nutrient reservoir (Hansell and Carlson, 2015). Studies increasingly recognize the need to connect findings from different analytical techniques in order to mitigate the limitations of any single technique and connect between disciplines, such as metabolomics and metagenomics (Moran et al., 2016). A crucial point to consider, however, is that the analytical windows of different methods usually only partially overlap. A suite of techniques to quantify and characterize DOM are available (Fellman et al., 2010; Mopper et al., 2007; Sandron et al., 2015). Some approaches, such as elemental analys is or absorbance and fluorescence spectroscopy can be used to characterize DOM in its original matrix at natural concentrations (Stedmon and Nelson, 2015), while other approaches such as nuclear magnetic resonance (NMR) spectroscopy or ultrahigh resolution mass spectrometry require sample enrichment and desalting prior to analys is (Mopper et al., 2007). Therefore, efforts to combine output from analytical techniques typically involve comparisons between bulk water samples and DOM extracts. However, many aspects of extraction remain poorly quantified. Specifically, there is a need for a comprehensive comparison of optical properties in bulk water versus extracted samples, in order to assess the severity of extraction-introduced biases and to guide methodological decisions in future studies.

Solid-phase extraction (SPE) is a popular method for the isolation of organic compounds and salt-removal due to relatively simple procedures, availability of prepacked cartridges, and relatively high dissolved organic carbon (DOC) recoveries. In recent years, PPL (styrene divinyl benzene polymer) has emerged as the most-popular extraction sorbent, able to extract an average of $43 \%$ of deep sea DOC and up to $65 \%$ of freshwater DOC (Dittmar et al., 2008). The increasing reliance on SPE sorbents has inspired studies focusing on their representativeness and selectivity primarily for molecular characterizations, since these analytical techniques largely rely on extracted DOM. For example, Raeke et al (2016) compared the ultrahigh resolution mass spectrometry characterization of terrestrial DOM in original (unextracted) versus isolated DOM using PPL and 
C18 resins and concluded that SPE did not significantly alter terrestrial DOM mass spectra since poorlyextracted compounds in any case equated to formulas that cannot be efficiently ionized by electrospray ionization (Raeke et al., 2016). However, a recent study of specific marine metabolites suggests that the picture may be more complex; extraction efficiencies for a set of 89 organic compounds varied between compounds and in some cases depended on the sample matrix for a given molecule (Johnson et al, 2017), suggesting that SPE can introduce biases depending on environmental conditions.

The effect of SPE using C18 sorbents on the optical properties of fluorescent (FDOM) and chromophoric $(\mathrm{CDOM})$ fractions has been investigated previously on the basis of raw fluorescence characteristics and absorbance spectral slopes. Green and Blough (1994) found that C18 extraction of freshwater DOM decreased CDOM absorbance spectral slopes (slope of an exponential curve fit to CDOM absorbance spectra) and was most efficient for long-wavelength FDOM, varying from $65 \%$ at $460 \mathrm{~nm}$ to $34 \%$ at $330 \mathrm{~nm}$. Boyle et al. (2009) subsequently verified this trend for a combination of freshwater and marine DOM. Recently, Andrew et al. (2016) also observed higher extraction efficiencies for long-wavelength CDOM but noted that original and extracted DOM had similar fluorescence quantum yields and responded similarly to $\mathrm{NaBH}_{4}$ reduction, indicating a high degree of similarity between extracted and original CDOM. However, few studies have compared original and extracted FDOM obtained with PPL sorbent, and only one has compared pre- and post-extraction samples using parallel factor analysis (PARAFAC) of emission-excitation matrix (EEM) fluorescence data sets (Murphy et al., 2018; Röttgers and Koch, 2012). Since EEM-PARAFAC is a widely-used technique for tracing FDOM fractions and correlations to other analytical measurements are increasingly being reported (Herzsprung et al., 2012; Kellerman et al., 2018; Stubbins et al., 2014), it is important to investigate the selectivity of extraction process for DOM fluorescence spectra.

The aim of this study was to compare the optical properties of bulk water DOM with PPL-extracted DOM originating from the same samples. Specifically, two hypotheses were tested: i) PPL-extraction reduces the variability in DOM optical properties by extracting similar DOM fractions in different samples; and ii) the 
efficiency of CDOM and FDOM extraction with PPL depends on the composition of DOM. These hypotheses were tested on the basis of spectral extraction efficiencies of bulk CDOM and FDOM, CDOM spectral slopes, PARAFAC spectra and fluorescence intensities, and apparent fluorescence quantum yields (AQYs). 


\section{Mate rials and Methods}

\section{Sample Collection}

Samples were collected onboard R/V Maria S Merian (cruise MSM56, Ecological Chemistry in Arctic Fjords) over a three-week period in July 2016. The transect encompassed three Fjords: Kongsfjorden (Longyearbyen), Scoresby Sound (East Greenland), and Arnarfjörður (West Iceland) spanning from $79^{\circ} \mathrm{N}$ to $65^{\circ} \mathrm{N}$ and $28^{\circ} \mathrm{W}$ to $12^{\circ} \mathrm{E}$ (Fig. S1).

Water samples were collected at variable depths $(1.5$ - $1470 \mathrm{~m})$ with a CTD Rosette equipped with Niskin bottles, and immediately filtered using pre-combusted GF/F filters $(0.7 \mu \mathrm{m}$, Whatman) by applying a vacuum of $<200$ mbar. Subsamples of the filtrate were stored in pre-combusted $40 \mathrm{~mL}$ amber glass vials at $4{ }^{\circ} \mathrm{C}$ in the dark and optical properties were measured within $6 \mathrm{~h}$ after filtration (see below). Samples for solid-phase extractions were immediately acidified ( $\mathrm{pH}$ 2) after filtration using concentrated hydrochloric acid (Suprapur grade, Merck) and stored in glass bottles at $4{ }^{\circ} \mathrm{C}$ in the dark until further processing. DOM was subsequently solid-phase extracted using PPL-resins as described previously (Dittmar et al., 2008). Briefly, PPL cartridges (200mg, Agilent Technologies) were rinsed with $6 \mathrm{~mL}$ methanol (Suprapur grade, Merck) and preconditioned with $6 \mathrm{~mL}$ acidified ultrapure water ( $\mathrm{pH} 2$ using hydrochloric acid, ultrapure water $>18.2 \mathrm{M} \Omega$ ). Five hundred $\mathrm{mL}$ acidified sample was applied to the cartridge under gravity and inorganic residues were subsequently removed with $6 \mathrm{~mL}$ acidified ultrapure water. Cartridges were dried using $\mathrm{N}_{2}$ (purity grade 5.5) and stored at $-20{ }^{\circ} \mathrm{C}$ until elution of DOM with ca. $600 \mu \mathrm{L}$ methanol (exact volume was determined for each sample by weight). Samples were subsequently stored at $-18^{\circ} \mathrm{C}$. In total, 191 FDOM samples and $216 \mathrm{CDOM}$ samples were taken that encompassed a salinity and temperature range of 10.6 to $35.1 \mathrm{PSU}$ and -1.7 to $11.7^{\circ} \mathrm{C}$, respectively (Table S1). 


\section{Spectroscopic measurements}

Spectroscopic measurements of original bulk water samples were carried out onboard. Fluorescence measurements of bulk samples were obtained using a HORIBA AquaLog fluorometer with a $10 \mathrm{~mm}$ quartz cuvette, while absorbance was measured using a Shimadzu UV2401PC spectrophotometer with a $100 \mathrm{~mm}$ quartz cuvette. Fluorescence emission was detected in the range of $240-600 \mathrm{~nm}$ (increment $\sim 3.3 \mathrm{~nm}$ ) with an integration time of $15 \mathrm{~s}$ at excitation wavelengths between $240 \mathrm{~nm}$ and $450 \mathrm{~nm}$ (increment $3 \mathrm{~nm}$ between 240 and $360 \mathrm{~nm}, 9 \mathrm{~nm}$ between 360 and $450 \mathrm{~nm}$ ). Accuracy of the excitation monochromator, emission detector, and the optical immaculacy of cuvettes were validated daily following a previously described protocol (Wünsch et al., 2015).

For extracted samples, $50 \mu \mathrm{L}$ of DOM extract (in methanol) was dried using a gentle stream of $\mathrm{N}_{2}$ at room temperature, reconstituted in $4 \mathrm{~mL} 150 \mathrm{mM}$ ammonium acetate $(\mathrm{pH} 7)$ in pre-combusted, amber glass vials, and equilibrated at room temperature for 30 minutes. These buffer conditions were chosen since additional sizeexclusion separations performed on the same samples necessitated these conditions. The possible influence of buffer conditions is discussed below. Since all extracted samples were measured in ammonium acetate, this buffer was also used as the spectroscopic blank and new blanks were measured for every batch of buffer. Due to sample volume constraints, fluorescence and absorbance of extracted samples were both measured using a HORIBA AquaLog with identical instrument settings (wavelength ranges and increments) compared to the original samples (except for a lower fluorescence integration time of $8 \mathrm{~s}$, accounting for higher concentrations). A separate absorbance measurement was carried out after the measurement of fluorescence EEMs to measure absorbance between 240 and $600 \mathrm{~nm}$ at increments matching the fluorescence excitation. Signals obtained in an SPE methanol extract $\mathrm{x}_{\text {methanol }}$ are related to the original signals $\mathrm{x}_{\text {org }}$ as follows:

$$
x_{\text {Methanol }}=x_{\text {org }} * \frac{V_{\text {extraction }}}{V_{\text {elution }}}, \text { (Eq. 1) }
$$


where $V_{\text {extraction }}$ is the volume of original water that was extracted $(0.5 \mathrm{~L})$, and $V_{\text {elution }}$ is the methanol elution volume (determined by weight for every sample, usually ca. $600 \mu \mathrm{L}$ ). EEM fluorescence and CDOM absorbance in a dried and reconstituted aliquot $\left(x_{\text {aliquot }}\right)$ can thus be corrected for the SPE enrichment to recover the original signal $x_{P P L}$ as follows:

$$
x_{P P L}=x_{\text {aliquot }} * \frac{V_{\text {elution }} * V_{\text {buffer }}}{V_{\text {extraction }} * V_{\text {aliquot }}},(\text { Eq. } 2)
$$

where, $V_{\text {buffer }}$ is the volume of ammonium acetate that the sample was reconstituted in $(0.004 \mathrm{~L})$, and $V_{\text {aliquot }}$ is the volume of methanol extract that was dried before reconstitution in ammonium acetate $(50 \mu \mathrm{L})$. This results in a unitless, sample-specific factor that is used to account for the enrichment during the extraction. Apparent extraction efficiencies $E$ were calculated as the ratio between extracted and original CDOM absorbance (as function of wavelength), FDOM fluorescence (as function of emission and excitation wavelengths), and $\mathrm{F}_{\max }{ }^{-}$ values of corresponding PARAFAC components (product of component score, and the spectral maximum of emission and excitation loadings, expressed in the same unit as fluorescence EEMs, i.e. Raman units) as follows:

$$
E=\frac{x_{P P L}}{x_{\text {org }}},(\text { Eq. 3) }
$$

where $x_{P P L}$ was the measured signal in the PPL extract, and $x_{\text {org }}$ was the corresponding signal measured in the original sample. Since the calculation of extraction efficiencies partially involves comparisons between signals with low overall intensities, some signal-to-noise-based filters were applied to exclude heavily affected signals from further analysis (Fig. S2, a detailed description can be found in the SI). It should be stressed that since absorbance and fluorescence are physical phenomena related to structural characteristics of organic compounds rather than intrinsic properties with known molar absorbance and fluorescence, the calculated values of $E$ represent apparent, rather than absolute, extraction efficiencies. 
The fluorescence data was processed in MATLAB (v9.4, Mathworks Inc.) using the $d r E E M$ toolbox [version 0.3.0, Murphy et al. (2013)]. Briefly, data were corrected for inner filter effects using the absorbance-based method (Kothawala et al., 2013) and normalized using the Raman peak area at $350 \mathrm{~nm}$ (integration between 378 and $424 \mathrm{~nm}$ ). Frist and $2^{\text {nd }}$ order physical scatter was removed and not interpolated. Freshness index (Wilson and Xenopoulos, 2009), fluorescence index (Cory and McKnight, 2005), S300-600 (Jerlov, 1968; Markager and Vincent, 2000), $S_{275-295}, S_{350-400}$ (Helms et al, 2008), and apparent fluorescence quantum yields (Wünsch et al., 2015) were calculated as described in the respective references. A summary of all optical parameters along with their definition and a description is listed in Table S2.

It should be noted that $\mathrm{pH}$ and ionic strength were sources of variation between bulk water and extract samples ( $\mathrm{pH} 7$, ionic strength $0.15 \mathrm{M}$ in extracts versus $\mathrm{pH} \sim 8$, ionic strength $0.2-0.7 \mathrm{M}$ in bulk waters). The impact of $\mathrm{pH}$ differences on CDOM and FDOM was investigated for a set of 10 diverse coastal and marine PPL extracts (Timko, 2015; Timko et al., 2015) and determined to be subtle (Table S3, Figs. S3-4; experimental details are provided in the SI). When comparing optical properties at $\mathrm{pH} 7$ to those at $\mathrm{pH} 8$, systematic differences in $\mathrm{pH}$ did not change CDOM spectral slopes by more than $0.75 \mu \mathrm{m}^{-1}$, did not change fluorescence indices significantly, led to relative changes of AQYs of $<2 \%$, and lowered extraction efficiencies by $<4 \%$. Additionally, our analyses indicated that changes in $\mathrm{pH}$ did not lead to significant changes in PARAFAC spectra of a Suwannee River NOM extract (International Humic Substances Society standard 2R101N). Past studies have concluded that the ionic strength of the matrix does not significantly affect FDOM EEMs (Boyd and Osburn, 2004; Mobed et al., 1996; Osburn et al., 2014), or the absorbance of bulk CDOM (Guo et al., 2007). However, more recent work concluded that ionic strength may influence CDOM absorbance in a similar fashion as $\mathrm{pH}$ (Gao et al., 2015). Thus, in addition to $\mathrm{pH}$, differences in the ionic strengths between bulk-water and DOM extracts could also have lowered the apparent extraction efficiencies of CDOM. However, since the range of ionic strengths range investigated in previous studies was outside the range of seawater samples measured in our study, a 
quantification of the effect was not possible. Further aspects of the inorganic matrix as source of error in comparisons between bulk samples and DOM extracts are discussed below, and in the SI (SI, Fig. S5).

\section{Chemometrics}

The underlying components of fluorescent DOM were isolated with PARAFAC using the $d r E E M$ toolbox for Matlab (Murphy et al., 2013). A set of 191 corresponding bulk water and extracted FDOM samples were independently modeled as separate datasets. Models with different numbers of components were explored (five to seven components). Ultimately, a six-component model was found to be most appropriate for both datasets. Both models were successfully validated using the split-half validation of random halves (Figures S6-7). The six component models had core consistencies of 1.5 and $1.4 \%$ and explained 99.5 , and $99.9 \%$ of the dataset variability for original samples and extracted FDOM, respectively. Components were named according to their fluorescence emission maximum. The Tucker congruence coefficient (TCC) was used to assess spectral similarity between PARAFAC fluorescence spectra of bulk water samples and extracted DOM (Lorenzo-Seva and ten Berge, 2006). The cut-off for sufficient spectral congruence was set as $\mathrm{TCC}_{\text {excitation }} \times \mathrm{TCC}_{\text {enission }}>0.95$.

To determine differences in parameters between original and extracted samples, one-sided analysis of variance tests (ANOVA) were performed. Furthermore, a principle component analysis (PCA) was carried out to explore relationships between extraction effic iencies of PARAFAC components and water mass and DOM composit ion. To do so, all included parameters were centered by subtracting the mean and scaled by dividing by the vector norm. 


\section{Results}

The optical properties of the original water samples were typical for marine DOM: CDOM absorbance increased approximately exponentially with decreasing wavelength and averaged $0.15 \pm 0.07 \mathrm{~m}^{-1}$ at $375 \mathrm{~nm}$. Examples of typical CDOM absorbance spectra and FDOM EEMs are shown in Figure S8. Spectral slopes averaged $20.5 \pm 2.8,28.1 \pm 2.9$, and $20.5 \pm 4.8 \mu \mathrm{m}^{-1}$ for $\mathrm{S}_{300-600}, \mathrm{~S}_{275-295}$, and $\mathrm{S}_{350-400}$, respectively. Fluorescence EEMs featured typical peaks consistent with peak A, T, M, and C (Coble, 2007) with averages of $0.04 \pm 0.01$, $0.02 \pm 0.007,0.02 \pm 0.008$, and $0.02 \pm 0.008$ Raman Units (R.U.), respectively.

\section{Spectral extraction efficiency of CDOM and FDOM}

For the sum of absorbance and fluorescence (referred to as bulk CDOM and FDOM), extraction efficiencies were significantly different (average values for bulk FDOM $39.0 \pm 5.8 \%$, and bulk CDOM 34.6 $\pm 7.5 \%$, onesided ANOVA $\mathrm{p}<0.01$ ). Spectral extraction efficiencies were calculated for every sample using CDOM absorbance spectra and FDOM fluorescence EEMs of original and extracted water samples. Average CDOM absorbance extraction efficiencies varied from a maximum of $39.5 \pm 12.3 \%$ at $363 \mathrm{~nm}$ to a minimum of $30.7 \pm 13.4 \%$ at $411 \mathrm{~nm}$. Efficiencies could not be reliably determined above $418 \mathrm{~nm}$ since more than $50 \%$ of CDOM absorbance measurements were below the limit of detection (Figure S2). Average CDOM extraction efficiencies generally featured two regions. The first was below ca. $360 \mathrm{~nm}$, where the average extraction efficiency showed an increase from $31.5 \pm 4.5 \%$ at $240 \mathrm{~nm}$ to the maximum at $363 \mathrm{~nm}$. The second region, from $363 \mathrm{~nm}$ to $411 \mathrm{~nm}$ featured steadily decreasing extraction efficiencies (Fig. 1a).

The bulk FDOM extraction efficiencies also varied spectrally but grouped in certain EEM wavelength regions (Fig 1b). Overall, extraction efficiencies seemed to follow fluorophore-like patterns in the wavelength ranges of predefined peaks (Coble, 2007). For example, high efficiencies of approximately $43 \pm 8 \%$ were observed in the region of peak C (excitation $260-350 \mathrm{~nm}$, emission $350-450 \mathrm{~nm}$ ). On the other hand, low efficiencies of approximately $31 \pm 6 \%$ were observed in the region of peak D (excitation $260-300 \mathrm{~nm}$, emission $450-$ 
$550 \mathrm{~nm})$. A second region with similarly low efficiencies was located at similar emission wavelengths at excitation $360-420 \mathrm{~nm}$. Higher, and more variable efficiencies were observed above excitation $340 \mathrm{~nm}$ and emission $500 \mathrm{~nm}$ (Fig. 1b-c).

\section{Absorbance and spectral slopes}

If extracted materials reflect the variability and underlying properties of their original samples, the spectral variability of CDOM absorbance within a dataset of extracts should mirror that of the original bulk water samples. In order to assess this, the standard deviations of CDOM spectra for each dataset were calculated. To focus on qualitative differences, all spectra were first divided by their integral, giving each sample a similar leverage. For simple, variable mixtures, the standard deviation of normalized spectra may reveal parts of the absorbance properties of underlying chromophores. However, the bulk-water standard deviation spectra did not reveal much structure, but rather featured two main regions (Fig. 2a). In the region between 240 and $300 \mathrm{~nm}$, variability was greatest, increasing towards shorter wavelengths. In the region above $300 \mathrm{~nm}$, the variability was lower with a broad peak centering at approximately $370 \mathrm{~nm}$. CDOM absorbance in solid-phase extracts showed notably less variability (lower standard deviations) than in the bulk water samples, and only near $300 \mathrm{~nm}$ was the standard deviation of both datasets similar in magnitude.

Spectral slopes of original and extracted CDOM were compared in order to investigate if solid-phase extractions impacted the overall values and relative changes of these popular optical proxies (Fig. 3a). With average values of $20.5 \pm 2.8$ and $20.5 \pm 1.7 \mu \mathrm{m}^{-1}, \mathrm{~S}_{300-600}$ did not differ significantly between original and extracted samples (one-sided analysis of variance (ANOVA), $\mathrm{p}=0.88$ ), although the variability was less for the extracted materials. Conversely, average values for the spectrally narrower slopes $S_{275-295}$ and $S_{350-400}$ differed between the bulk water samples and the solid phase extracts. $\mathbf{S}_{275-295}$ was significantly lower in the extracts, having an average of $28.1 \pm 2.9$ in bulk water samples but only an average of $26.0 \pm 2.4 \mu \mathrm{m}^{-1}$ in extracts, while $S_{350-400}$ on the contrary increased from an average of $20.5 \pm 4.8$ to $24.3 \pm 3.3 \mu \mathrm{m}^{-1}$ (one-sided ANOVA p<0.01 in both 
cases). While all spectral slopes of extracted samples were significantly correlated to bulk water samples ( $\mathrm{p}<0.01$, Fig. S9), Pearson $\mathrm{R}^{2}$-values were low $\left(0.30,0.52,0.07\right.$, for $\mathrm{S}_{300-600}, \mathrm{~S}_{275-295}, \mathrm{~S}_{350-400}$, respectively). $\mathrm{S}_{300-}$ 600 has been shown to increase with decreasing molecular size (Green and Blough, 1994; Wünsch et al., 2018), but its relationship with $\mathrm{a}_{375}$ has also been used to indicate qualitative differences between CDOM from different sources (Stedmon and Markager, 2001). The comparison between original samples and extracted material clearly indicated a loss of variability in extracted samples and a significant alteration of the relationship between $S_{300-600}$ and $\mathrm{a}_{375}$ (Fig. S10).

\section{Fluorescence}

As seen with absorbance, the variability in the fluorescence of the extracted materials was lower than in the bulk samples (Fig. 2b-c). In the area of peak T (Ex / Em 275 / $350 \mathrm{~nm}$ ), the standard deviation was lower in extracted materials by a factor of two, while in the area of peak D (excitation $>380 \mathrm{~nm}$, emission $>450 \mathrm{~nm}$ ), it was higher by a factor of up to 1.5 , and equal in the area of peak $A$ and $C$ (excitation 260 - 300, emission 400 - 500). It was also notable that compared to the bulk water FDOM standard deviation EEM, the extracted materials showed more distinct gaussian-shaped peaks (Fig. 2c, e.g. excitation $300 \mathrm{~nm}$, emission $400 \mathrm{~nm}$ and excitation $430 \mathrm{~nm}$, emission $510 \mathrm{~nm}$ ). Fluorescence index and freshness index decreased significantly from $1.67 \pm 0.12$ to $1.56 \pm 0.05$, and $0.90 \pm 0.09$ to $0.81 \pm 0.05$ (one-sided ANOVA $\mathrm{p}<0.01$ in both cases, Fig. 3b). Moreover, while significantly correlated $(\mathrm{p}<0.01)$, the freshness and fluorescence index of extracted samples was a poor predictor of corresponding values in bulk water samples (Pearson $\mathrm{R}^{2} 0.08$, and 0.31 , for fluorescence and freshness index, respectively, Fig. S9). Apparent fluorescence quantum yields increased significantly in the range of excitation 261 to $351 \mathrm{~nm}$. For example, at $276 \mathrm{~nm}$, AQYs increased from an average of $1.66 \pm 0.31 \%$ in bulk water samples to $3.12 \pm 0.35 \%$ for extracted samples (one-sided ANOVA $p<0.01$, Fig. 3b). Similar to the fluorescence indices above, the AQY of extracted samples at $276 \mathrm{~nm}$ was also not a good indicator of the corresponding bulk water AQYs (Pearson $\mathrm{R}^{2}=0.29, \mathrm{p}<0.01$, Fig. S9). 
For each of the bulk water and solid-phase extracted FDOM data sets, a six-component PARAFAC model was successfully validated. The model of the bulk water samples featured components with emission maxima at 330, $350,410,420,440$, and $500 \mathrm{~nm}$ (components will henceforth be referred to by these emission maxima). A sixcomponent model of the extracts was only slightly different (Fig. 4). $\mathrm{C}_{350}, \mathrm{C}_{410}$, and $\mathrm{C}_{420}$ exhibited Tucker congruence values exceeding 0.96 , while $\mathrm{C}_{330}, \mathrm{C}_{440}$ and $\mathrm{C}_{500}$ differed in either their excitation or emission spectrum, resulting in overall congruence values between 0.88 and 0.91 (Table S4).

Under the assumption that the components in each model (Fig. 4) corresponded directly despite partially changed spectral properties, $\mathrm{F}_{\max }$-values were compared. In all but seven of 1,146 paired comparis ons (6 components in 191 samples, $0.6 \%), \mathrm{F}_{\max }$ of the extracted PARAFAC component was lower than in the original sample FDOM (Fig. 3c, one-sided ANOVA, p-value < 0.01). Also, for all components, the variability in $F_{\max }$ values was much lower in the extracted than the bulk samples (Fig. 3c). Average extraction efficiencies were different for all components, averaging $45 \pm 14 \%, 58 \pm 18 \%, 49 \pm 15 \%, 37 \pm 15 \%, 32 \pm 7 \%$, and $17 \pm 4 \%$ for $\mathrm{C}_{330}, \mathrm{C}_{350}, \mathrm{C}_{410}, \mathrm{C}_{420}, \mathrm{C}_{440}$, and $\mathrm{C}_{500}$, respectively (Table 1). Extraction efficiencies varied visually between components with respect to their distribution (Fig. 5). Compared to the bulk FDOM extraction efficiency (average $39.0 \pm 5.8 \%$ ), $\mathrm{C}_{410}$ and $\mathrm{C}_{350}$ extracted with greater efficiencies, while $\mathrm{C}_{500}$, and $\mathrm{C}_{440}$ were extracted less efficiently and $\mathrm{C}_{420}$ most closely followed the bulk FDOM extraction efficiency. The distribution of extraction efficiencies of all components did not resemble unimodal normal distributions; rather, they featured visibly distinct, overlapping populations of extraction efficiencies (Fig. 5). With the exception of $\mathrm{C}_{420}$, the $\mathrm{F}_{\max }$-values of extracted PARAFAC components were relatively poor predictors of bulk water fluorescence (Fig. S11). In all comparisons, $\mathrm{F}_{\max }$-values of extracted samples were significantly correlated with corresponding bulk water values ( $\mathrm{p}<0.01$ ), although $\mathrm{R}^{2}$-values were generally relatively low (Pearson $R^{2}=0.14\left(\mathrm{C}_{310}\right), 0.38\left(\mathrm{C}_{350}\right), 0.66$ $\left(\mathrm{C}_{410}\right), 0.71\left(\mathrm{C}_{440}\right)$, and $\mathrm{R}^{2}=0.42$ for $\left.\mathrm{C}_{500}\right)$. However, $\mathrm{F}_{\max }$ of the extracted $\mathrm{C}_{420}$ was a good predictor of the bulk sample fluorescence intensities of $\mathrm{C}_{420}\left(\mathrm{R}^{2}=0.92\right)$. 
Since multiple factors, such as salinity, sample origin, and DOM composition may influence the extraction of DOM, a PCA model was used to explore the variation in extraction efficiencies of spectrally congruent PARAFAC components $\left(\mathrm{C}_{350}, \mathrm{C}_{410}, \mathrm{C}_{420}\right)$ along with CDOM absorbance at $254 \mathrm{~nm}$. Principle components one (PC1) and two (PC2) explained 29.48 and $21.45 \%$ of the variability (Fig. 6). The extraction efficiency of $\mathrm{C}_{410}$ was negatively correlated to salinity, while the extraction efficiencies of $\mathrm{C}_{350}, \mathrm{C}_{420}$, and $\mathrm{CDOM}$ absorbance at $254 \mathrm{~nm}$ were correlated with spectral slope values. 


\section{Discussion}

The extraction of DOM using the PPL resin led to a reduction in absorbance and fluorescence signals (Figs. 1,3,5), as well as changes in spectral properties of CDOM and FDOM (Figs. 2,4). These differences between bulk samples and extracted DOM may originate from the extraction process itself but can also be caused by disturbances that affect the comparison attempted in this study. In the following section, we first evaluate the various sources of error and then proceed to discuss the potential impact of solid-phase extraction on the optical properties of DOM.

\section{Matrix effects and modeling arte facts}

Before attributing differences of optical properties (Figs. 2 -4) between bulk water and extracted DOM to the selectivity of the extraction process with PPL, the potential influence of different sources of error should be evaluated. Here, we consider three potential sources of error and attempt to quantify their relative importance in this study. (i): Differences in the inorganic matrix of bulk water and extracted DOM influencing the optical properties of chromophores; (ii): The partial removal of non-chromophoric DOM during the extraction causing changes in optical properties of extracted DOM; (iii): Different signal-to-noise ratios and overall noise structures in bulk water and extract DOM data sets leading to artefacts in comparisons and PARAFAC modeling.

The inorganic matrix as a potential source of error (point $i$ above) requires the consideration of two factors. Firstly, since absorbance and fluorescence are physical phenomena, they depend on the solvent used during measurements. Compared to the average seawater conditions ( $\mathrm{pH} \mathrm{8,} \mathrm{ionic} \mathrm{strength} 0.7 \mathrm{M}$ ), extracts were measured at lower $\mathrm{pH}$ and lower ionic strength ( $\mathrm{pH} 7$, ionic strength $0.15 \mathrm{M}$ ). Based on previous work (Boyd and Osburn, 2004; Guo et al., 2007; Mobed et al., 1996), as well as on a pH titration experiment (see SI, Figs. S2-3), we conclude the potential bias introduced by systematic differences in the inorganic sample matrix did not exceed the uncertainties reported for optical parameters and extraction efficiencies. 
Secondly, there will inevitably be differences in the inorganic matrix between bulk DOM (featuring a variable inorganic matrix, especially when spanning a large geographical range) and DOM extracts (featuring constant solvent composition) that may introduce artificial differences between bulk samples and extracted DOM. If bulk water matrices significantly impact the spectral characteristics of DOM fluorescence moieties, then they will also affect the PARAFAC decomposition. In contrast, in PPL extracts measured at constant conditions, there will be no spectral shifts caused by the inorganic matrix. Our investigation on the influence of pH (Fig. S2-3), and previous work focusing on ionic strength (Boyd and Osburn, 2004) indicated that $\mathrm{pH}$ and ionic strength would not have impacted the fluorescence properties sufficiently to explain changes observed in our study (Figs. 2, 3ab, 4). In contrast, for CDOM absorbance, a recent study estimated the effect of ionic strength and found it to be similar to the effect of $\mathrm{pH}$ (Gao et al., 2015). Since, in this study, bulk CDOM was measured across a wide salinity range (10.6 - 35.1 PSU), the variability of bulk CDOM (Fig. 2a) could have in part reflect changes in ionic strengths between samples. However, our investigation of absorbance in different salinity ranges indicated that compositional change, rather than ionic strength, was the primary mechanis m for variability in bulk CDOM (SI, Fig. S5). The differences in optical properties caused by variable bulk-water matrices thus appeared to fall within the range of uncertainty associated with characterizing a large sample set.

The loss of non-chromophoric DOM during the extraction (point ii above) may also have contributed to the differences in optical properties between bulk sample and extracted DOM through the conformational reorganization of extracted DOM. Significant changes in the optical properties of Tryptophan, caused by interactions with non-chromophoric moieties in peptides and proteins, have been demonstrated (Vivian and Callis, 2001). The loss of high-molecular size DOM in extracts hints at conformational changes when DOM undergoes extraction (Raeke et al., 2016). However, compared to amino-acid fluorescence in proteins, the relationship between the three-dimens ional supramolecular assembly of DOM and its optical properties is not well understood. For fluorophores in pure solutions, the position and broadness of fluorescence emission is generally connected to the degree of double bond conjugation, while the substitution of the central aromatic 
structure influences a fluorophore's absorbance spectrum (Wünsch et al., 2015). The exact three-dimensional assembly of DOM could have similar impacts through electronic interactions between quasi-stable assemblies that may change after the removal of a significant portion of DOC. For the PARAFAC components in our study, relatively low spectral similarity of $\mathrm{C}_{330}, \mathrm{C}_{440}$, and $\mathrm{C}_{500}$ was due to significant matches in either excitation or emission spectra and disagreement in the other spectrum. In the light of a conformational reorganization of DOM, this could indicate distinct changes in the assemblies influencing the properties of DOM's chromophores. However, due to the complexity of DOM, the conformational changes remain unknown and the ir exact impact on the optical properties of extracted DOM cannot be quantified.

Finally, artefacts stemming from different noise level and structures in the compared data sets (point iii above) can also be a significant source of error, particularly for PARAFAC modeling. Due to the nature of the respective samples, both investigated data sets have different average signal-to-noise ratios (Fig. S7), feature different overall noise-structures (Fig. 2b-c), and show different degrees of autocorrelation between concentrations of DOM constituents (here: chromophores). Importantly, these factors do not necessarily favor the analysis of DOM extracts over bulk samples, and strongly depend on the dataset. The significant influence of measurement noise was particularly visible in bulk CDOM extraction efficiencies (Fig. 1), where the uncertainty in extraction efficiencies exceeded the potential influence of $\mathrm{pH}$ and ionic strength (as discussed above). Moreover, the lower absorbance values registered in DOM extracts in particular led to the exclusion of many samples at wavelengths $>400 \mathrm{~nm}$ and thus prevented the reliable determination of extraction efficiencies at these wavelengths.

While the carbon concentration, and thus signal-to-noise ratios in extracts would be expected to favor DOM extracts, the selective extraction process (as discussed below) might lead to increased levels of autocorrelation between fluorescence signals. In severe cases, the occurrence autocorrelated fluorescence components violates the variability assumption of PARAFAC and can lead to physically and chemically meaningless model solutions (Murphy et al., 2013). In the present study, such correlations were overall not severe, but occurred less severely 
in the bulk sample data set $\left(0.01<\mathrm{R}^{2}<0.8\right.$, average 0.27$)$ compared to the DOM extracts $\left(0.17<\mathrm{R}^{2}<0.82\right.$, average 0.55 ). Thus, the combined modeling of both data sets could improve adherence to the variability assumption of PARAFAC. However, attempts to fit one model to both data sets, or fitting the extract DOM model to bulk samples (and vice versa) led to significant residuals or improper representations of fluorescence in one or both data sets. While difficult to quantify, modeling artefacts likely influenced the PARAFAC solutions to some degree since a recent study has demonstrated that PPL extracts contain spectrally indistinguishable fluorescence fractions compared to their bulk samples (Murphy et al., 2018). In cases where changes in fluorescence properties are apparent $\left(\mathrm{C}_{330}, \mathrm{C}_{440}, \mathrm{C}_{500}\right)$ caution is warranted when interpreting apparent extraction efficiencies, as the reported values can be severely influenced by modeling artefacts. The respective components were therefore excluded from in-depth analysis (e.g. Fig. 6).

\section{Impact of solid-phase extractions on CDOM absorption}

The PPL-resin extracted CDOM with spectrally-variable extraction efficiencies, indicating selectivity in the extraction procedure. The CDOM extraction efficiencies for PPL were similar to those previously reported for the C18 resin (Green and Blough, 1994). However, PPL extracted less long-wavelength absorbing CDOM. This coincided with a loss of spectral variability in extracted materials, particularly at long wavelengths $(>370 \mathrm{~nm})$. Because long-wavelength absorbing CDOM is associated with larger-average-molecular-size DOM (Helms et al., 2008; Reader et al., 2015), the low recovery of CDOM at long wavelengths could point towards a loss of large- molecular-size material during the extraction with PPL. However, we observed no significant changes in $S_{300-600}$ for PPL extracts, although average values of $S_{275-295}$ increased and $S_{350-400}$ decreased significantly. Also, considering that none of the spectral slopes in extracted samples were accurate predictors of bulk water CDOM slopes, our results point towards complex qualitative changes in CDOM rather than a preferential extraction of certain size fractions. The relationship between $S_{300-600}$ and $a_{375}$ in extracted samples furthermore showed that PPL extractions reduced spectral variation in CDOM by extracting particular fractions of CDOM (Figure S9). This selectivity seemed in part to depend on the character of the bulk DOM that was subjected to extraction, 
since the PCA analysis indicated covariance between CDOM extraction efficiency at $254 \mathrm{~nm}$ and shifts in DOM character as observed by $\mathrm{S}_{300-600}$ (Fig. 6). Together, these results indicate that solid-phase extracts do not accurately reflect the variability of bulk water samples.

There is evidence that long-wavelength absorption by CDOM may arise from charge transfer interactions between donor and acceptor molecules (Del Vecchio and Blough, 2004) although this has been recently challenged (McKay et al., 2018). In the context of the charge-transfer hypothesis, the preferential loss of, and decreased variability in, long-wavelength absorbance, may point towards a disruption of charge-transfer in DOM extracted with PPL. Andrew et al. (2016) reported that the C18-resin retains long-wavelength absorbing material efficiently and that $\mathrm{C} 18$ extract responded similarly to chemical reduction with $\mathrm{NaBH}_{4}$ compared to bulk water DOM, indicating representative recovery of the moieties involved in charge-transfer interactions. Thus, PPLextractions appear to show opposite selectivity compared to C18 extractions. Comparisons between C18 and PPL extracts could aid the investigation of charge-transfer as potential model for the photophysics of CDOM.

\section{Impact of solid-phase extractions on FDOM properties}

The wavelength dependence of FDOM extraction efficiencies (Fig. 1b) indicated that PPL did not recover different FDOM fractions equally well. Green and Blough (1994) reported that C18 recovers between 34 and $65 \%$ of FDOM at different excitation wavelengths. Here, the PPL resin recovered $39 \%$ of FDOM on average, which is similar to typical DOC recovery rates of around $43 \%$ (Dittmar et al., 2008). The fact that bulk FDOM extraction efficiencies were in the same range as bulk DOC suggests that the loss of DOC during extractions is reflected in a comparable loss of FDOM. However, the extraction process impacted the composition of FDOM. For example, the fluorescence and freshness index, both popular proxies used to indicate compositional changes of DOM, were decreased by extraction [making extracts appear to be both 'more terrestrial' and 'older' than bulk samples (Cory and McKnight, 2005; Parlanti et al., 2000)], suggesting a change in character that did not 
reflect the bulk water samples. Moreover, none of the investigated fluorescence indices of extracted samples accurately reflected the changes in bulk water samples $\left(\mathrm{R}^{2}<0.31\right.$ in all cases).

Spectral decomposition of the fluorescence data using PARAFAC revealed that extracted and original FDOM consisted of spectrally-similar underlying fluorescence components. Components $\mathrm{C}_{350}, \mathrm{C}_{410}$, and $\mathrm{C}_{420}$ were indistinguishable in both the bulk water and extracted data sets, indicating that solid-phase extractions retained the characteristics of the associated fluorophores, whereas spectral differences were observed for $\mathrm{C}_{330}, \mathrm{C}_{440}$, and $\mathrm{C}_{500}$. The recovery rates of spectrally unchanged fluorescence components differed significantly from the average rates found for bulk FDOM. High variability in average recovery rates also led to an inaccurate reflection of bulk water $\mathrm{F}_{\mathrm{max}}$-values by corresponding extracts. The principle component analys is revealed that extraction efficiencies of PARAFAC components were partially-correlated to water mass and DOM characteristics. However, $\mathrm{C}_{420}$ was a notable exception, since its extraction efficiency was least influenced by DOM composition or water mass characteristics (Fig. 6), and $\mathrm{C}_{420}$ 's fluorescence intensities were stronglycorrelated between extracts and corresponding bulk water samples.

In addition to providing a means to concentrate DOM and separate it from its saline matrix, solid-phase extraction can also be seen as a simple chromatographic technique that distinguishes two DOM fractions based on their affinity to the resin (retained and lost during the extraction). Importantly, if PPL extracts are representative of bulk water DOM, then recoveries should be similar for all fractions. Moreover, if PARAFAC components are specific proxies for distinct, isolated chemical compounds, then extraction efficiencies should be normally distributed since they would interact with PPL in a characteristic, predictable fashion. However, numerous recent studies indicate that fluorescence components are part of supramolecular assemblies with larger molecular size (Cuss and Guéguen, 2015; Romera-Castillo et al., 2014; Wünsch et al., 2018, 2017) and that a single fluorescence component may track a range of molecular formulas (Herzsprung et al., 2012). Consistent with the picture that fluorescence components represent extremely diverse classes of DOM, PARAFAC components were recovered with variable average extraction efficiencies. Since PPL is known to retain 
moderately-polar to nonpolar substances (Dittmar et al., 2008), these components must be associated with a wide range of DOM of varying hydrophobicity.

Previous studies have directly correlated measurements on bulk DOM with measurements on DOM extracts in order to identify apparent links (Herzsprung et al., 2012; Kellerman et al., 2018; Stubbins et al., 2014). For example, Stubbins et al. (2014) reported that protein-like fluorescence (similar to $\mathrm{C}_{330}$ and $\mathrm{C}_{350}$ in our study) correlated with $14 \%$ of molecular formulas detected in PPL extracts, while a long-wavelength fluorescence component (resembling $\mathrm{C}_{500}$ in our study) correlated with fewer than $1 \%$ of formulas. Since our results indicate that $\mathrm{C}_{350}$ should be extracted with much higher efficiency (58\%) than $\mathrm{C}_{500}(17 \%)$, this result may in part be attributable to differences in extraction efficiencies. Stronger correlations, in particular for poorly extracted components, can likely be established in future studies if both measurements are performed on extracted samples. 


\section{Implications and perspectives}

Our findings have important implications for studies seeking to combine DOM optical measurements with molecular-level characterizations of extracted DOM in the pursuit of either rapid approaches to tracing specific DOM fractions, or a better understanding of the origins of the optical signals. While bulk water and extracted DOM contain similar fluorescence fractions, their relative proportions differ. Also, the extraction process serves to homogenise DOM composition trough the inherent selectivity of the extraction resin. Therefore, if relationships exist between the molecular characteristics and optical properties of extracted DOM, it is likely that they can be extrapolated to bulk samples. However, links between chemical and optical DOM datasets should always be established using measurements performed on samples subject to identical pre-treatment (e.g. PPL extraction). Routinely measuring optical properties on both bulk water and extracted DOM would be valuable since it would allow extrapolation of these established relationships to bulk water DOM.

The recovery of DOM optical signatures in this study depended partly on water mass and DOM characteristics. Apparent differences between samples at the opposite ends of environmental gradients may therefore reflect extraction biases in addition to differences in DOM source material. Our study highlights the potential for misrepresenting bulk DOM biogeochemistry when relying on a single, selective sample pre-processing technique. However, this risk also extends to the widespread reliance on single characterization techniques. It is thus of great importance that analytical techniques that exclusively characterize extracted materials are linked to techniques that are capable of characterizing both bulk water and extracted samples. This is necessary to leverage the superior analytical depth of advanced techniques relying on DOM extracts, such as high-resolution mass spectrometry, to interpret in-situ DOM measurements that provide superior spatio-temporal resolution, such as in situ fluorescence and absorbance sensors. 


\section{Acknowledgements}

This study was in part funded by the Danish Council for Independent Research-Natural Sciences Grant DFF1323-00336 and Nordic5Tech collaborative funding (Technical University of Denmark). KRM and UJW acknowledge funding from the Swedish Research Council (FORMAS 2017-00743). We thank the crew and captain of R/V Maria $\mathrm{S}$ Merian for their assistance during the cruise MSM56 (Deutsche Forschungsgeme inschaft; Senatskommission für Ozeanographie Cruise; MSM56 [MerMet 14-15 Koch]). The authors would like to thank Claudia Burau for her help during sampling and solid-phase extractions. UJW and CAS would like to thank Astrid Bracher and Rafael Gonçalves-Araujo for kindly providing a spectrofluorometer for onboard measurements. UJW thanks Michael Gonsior and Stephen Timko for kindly providing the $\mathrm{pH}$ titration data. 


\section{References}

Boyd, T.J., Osburn, C.L., 2004. Changes in CDOM fluorescence from allochthonous and autochthonous sources during tidal mixing and bacterial degradation in two coastal estuaries. Mar. Chem. 89, 189-210. https://doi.org/10.1016/j.marchem.2004.02.012

Coble, P.G., 2007. Marine optical biogeochemistry: The chemistry of ocean color. Chem. Rev. 107, 402-418. https://doi.org/10.1021/cr050350+

Cory, R.M., McKnight, D.M., 2005. Fluorescence spectroscopy reveals ubiquitous prese nce of oxidized and reduced quinones in dissolved organic matter. Environ. Sci. Technol. 39, 8142-8149. https $/ / d o i . o r g / 10.1021 / e s 0506962$

Cuss, C.W., Guéguen, C., 2015. Relationships between molecular weight and fluorescence properties for size- fractionated dissolved organic matter from fresh and aged sources. Water Res. 68, 487497. https://doi.org/10.1016/j.watres.2014.10.013

Del Vecchio, R., Blough, N. V., 2004. On the origin of the optical properties of humic substances. Environ. Sci. Technol. 38, 3885-3891. https://doi.org/10.1021/es049912h

Dittmar, T., Koch, B.P., Hertkorn, N., Kattner, G., 2008. A simple and efficient method for the solidphase extraction of dissolved organic matter (SPE-DOM) from seawater. Limnol. Ocean. Methods 6, 230-235. https://doi.org/10.4319/lom.2008.6.230

Fellman, J.B., Hood, E., Spencer, R.G.M., 2010. Fluorescence spectroscopy opens new windows into dissolved organic matter dynamics in freshwater ecosystems: A review. Limnol. Oceanogr. 55, 2452-2462. https://doi.org/10.4319/lo.2010.55.6.2452 
Gao, Y., Yan, M., Korshin, G. V., 2015. Effects of Ionic Strength on the Chromophores of Dissolved Organic Matter. Environ. Sci. Technol. 49, 5905-5912. https//doi.org/10.1021/acs.est.5b00601

Green, S.A., Blough, N. V., 1994. Optical absorption and fluorescence properties of chromophoric dissolved organic matter in natural waters. Limnol. Oceanogr. 39, 1903-1916. https//doi.org/10.4319/lo.1994.39.8.1903

Guo, W., Stedmon, C.A., Han, Y., Wu, F., Yu, X., Hu, M., 2007. The conservative and nonconservative behavior of chromophoric dis solved organic matter in Chinese estuarine waters. Mar. Chem. 107, 357-366. https://doi.org/10.1016/j.marchem.2007.03.006

Hansell, D.A., Carlson, C.A., 2015. Biogeochemistry of Marine Dissolved Organic Matter, Biogeochemistry of Marine Dissolved Organic Matter. https://doi.org/10.1016/B978-0-12405940-5.00004-2

Helms, J.R., Stubbins, A., Ritchie, J.D., Minor, E.C., Kieber, D.J., Mopper, K., 2008. Absorption spectral slopes and slope ratios as indicators of molecular weight, source, and photobleaching of chromophoric dissolved organic matter. Limonology Oceanogr. 53, 955-969. https//doi.org/10.4319/10.2008.53.3.0955

Herzsprung, P., Von Tümpling, W., Hertkorn, N., Harir, M., Büttner, O., Bravidor, J., Friese, K., Schmitt-Kopplin, P., 2012. Variations of DOM quality in inflows of a drinking water reservoir: Linking of van krevelen diagrams with EEMF spectra by rank correlation. Environ. Sci. Technol. 46, 5511-5518. https//doi.org/10.1021/es300345c

Jerlov, N.G., 1968. Optical Oceanography. Elsevier $\quad$ Oceanogr. $\quad$ Ser. 5199. 
https//doi.org/10.1016/0031-8663(69)90017-9

Johnson, W.M., Kido Soule, M.C., Kujawinski, E.B., 2017. Extraction efficiency and quantification of dissolved metabolites in targeted marine metabolomics. Limnol. Oceanogr. Methods 15, 417-428. https:/doi.org/10.1002/lom3.10181

Kellerman, A.M., Guillemette, F., Podgorski, D.C., Aiken, G.R., Butler, K.D., Spencer, R.G.M., 2018. Unifying Concepts Linking Dissolved Organic Matter Composition to Persistence in Aquatic Ecosystems. Environ. Sci. Technol. 52, 2538-2548. https//doi.org/10.1021/acs.est.7b05513

Kothawala, D.N., Murphy, K.R., Stedmon, C.A., Weyhenmeyer, G.A., Tranvik, L.J., 2013. Inner filter correction of dissolved organic matter fluorescence. Limnol. Oceanogr. Methods 11, 616-630. https//doi.org/10.4319/lom.2013.11.616

Lorenzo-Seva, U., ten Berge, J.M.F., 2006. Tucker's congruence coefficient as a meaningful index of factor similarity. Methodology 2, 57-64. https://doi.org/10.1027/1614-2241.2.2.57

Markager, S., Vincent, W., 2000. Spectral light attenuation and the Absoption of UV and blue light in natural waters. Limnol, Oceanogr.

McKay, G., Korak, J.A., Erickson, P.R., Latch, D.E., McNeill, K., Rosario-Ortiz, F.L., 2018. The Case Against Charge Transfer Interactions in Dissolved Organic Matter Photophysics. Environ. Sci. Technol. 52, 406-414. https://doi.org/10.1021/acs.est.7b03589

Mobed, J.J., Hemmingsen, S.L., Autry, J.L., Mcgown, L.B., 1996. Fluorescence characterization of IHSS humic substances: Total luminescence spectra with absorbance correction. Environ. Sci. 
Technol. 30, 3061-3065. https://doi.org/10.1021/es9601321

Mopper, K., Stubbins, A., Ritchie, J.D., Bialk, H.M., Hatcher, P.G., 2007. Advanced instrumental approaches for characterization of marine dissolved organic matter: Extraction techniques, mass spectrometry, and nuclear magnetic resonance spectroscopy. Chem. Rev. 107, 419-442. https $/ /$ doi.org/10.1021/cr050359b

Moran, M.A., Kujawinski, E.B., Stubbins, A., Fatland, R., Aluwihare, L.I., Buchan, A., Crump, B.C., Dorrestein, P.C., Dyhrman, S.T., Hess, N.J., Howe, B., Longnecker, K., Medeiros, P.M., Niggemann, J., Obernosterer, I., Repeta, D.J., Waldbauer, J.R., 2016. Deciphering ocean carbon in a changing world. Proc. Natl. Acad. Sci. 113, 3143-3151. https//doi.org/10.1073/pnas.1514645113

Murphy, K., Timko, S., Gonsior, M., Powers, L., Wünsch, U., Stedmon, C., 2018. Photochemistry illuminates ubiquitous organic matter fluorescence spectra. Environ. Sci. Technol. https $/ /$ doi.org/10.1021/acs.est.8b02648

Murphy, K.R., Stedmon, C.A., Graeber, D., Bro, R., 2013. Fluorescence spectroscopy and multi-way techniques. PARAFAC. Anal. Methods 5, 6557-6566. https://doi.org/10.1039/c3ay41160e

Osburn, C.L., Del Vecchio, R., Boyd, T.J., 2014. Physicochemical Effects on Dissolved Organic Matter Fluorescence in Natural Waters, in: Coble, P., Lead, J., Baker, A., Reynolds, D.M., Spencer, R.G.M. (Eds.), Aquatic Organic Matter Fluorescence. Cambridge University Press, Cambridge, pp. 233-277. https://doi.org/10.1017/CBO9781139045452.012

Parlanti, E., Wörz, K., Geoffroy, L., Lamotte, M., 2000. Dissolved organic matter fluorescence 
spectroscopy as a tool to estimate biological activity in a coastal zone submitted to anthropogenic inputs. Org. Geochem. 31, 1765-1781. https://doi.org/10.1016/S0146-6380(00)00124-8

Raeke, J., Lechtenfeld, O.J., Wagner, M., Herzsprung, P., Reemtsma, T., 2016. Selectivity of solid phase extraction of freshwater dissolved organic matter and its effect on ultrahigh resolution mass spectra. Environ. Sci. Process. Impacts 18, 918-927. https//doi.org/10.1039/C6EM00200E

Reader, H.E., Stedmon, C.A., Nielsen, N.J., Kritzberg, E.S., 2015. Mass and UV-visible spectral fingerprints of dissolved organic matter: sources and reactivity. Front. Mar. Sci. 2, 1-10. https $/ /$ doi.org/10.3389/fmars.2015.00088

Romera-Castillo, C., Chen, M., Yamashita, Y., Jaffé, R., 2014. Fluorescence characteristics of sizefractionated dissolved organic matter: Implications for a molecular assembly based structure? Water Res. 55, 40-51. https://doi.org/10.1016/j.watres.2014.02.017

Röttgers, R., Koch, B.P., 2012. Spectroscopic detection of a ubiquitous dissolved pigment degradation product in subsurface waters of the global ocean. Biogeosciences 9, 2585-2596. https://oi.org/10.5194/bg-9-2585-2012

Sandron, S., Rojas, A., Wilson, R., Davies, N.W., Haddad, P.R., Shellie, R.A., Nesterenko, P.N., Kelleher, B.P., Paull, B., 2015. Chromatographic methods for the isolation, separation and characterisation of dissolved organic matter. Environ. Sci. Process. Impacts 17, 1531-1567. https $/ /$ doi.org/10.1039/c5em00223k

Stedmon, C.A., Markager, S., 2001. The optics of chromophoric dissolved organic matter (CDOM) in the Greenland Sea: An algorithm for differentiation between marine and terrestrially derived 
organic matter. Limnol. Oceanogr. 46, 2087-2093. https://doi.org/10.4319/lo.2001.46.8.2087

Stedmon, C.A., Nelson, N.B., 2015. The Optical Properties of DOM in the Ocean, in: Hansell, D.A., Carlson, C.A. (Eds.), Biogeochemistry of Marine Dissolved Organic Matter. Elsevier Inc., San Diego, pp. 481-508. https//doi.org/10.1016/B978-0-12-405940-5.00010-8

Stubbins, A., Lapierre, J.-F., Berggren, M., Prairie, Y.T., Dittmar, T., del Giorgio, P.A., 2014. What's in an EEM? Molecular Signatures Associated with Dissolved Organic Fluorescence in Boreal Canada. Environ. Sci. Technol. 48, 10598-10606. https://doi.org/10.1021/es502086e

Timko, S.A., 2015. Photochemistry of Dissolved Organic Matter: Reactivity and application in constructed treatment wetlands. University of California, Irvine.

Timko, S.A., Gonsior, M., Cooper, W.J., 2015. Influence of pH on fluorescent dissolved organic matter photo-degradation. Water Res. 85, 266-274. https://doi.org/10.1016/j. watres.2015.08.047

Vivian, J.T., Callis, P.R., 2001. Mechanisms of tryptophan fluorescence shifts in proteins. Biophys. J. 80, 2093-2109. https $/ /$ doi.org/10.1016/S0006-3495(01)76183-8

Wilson, H.F., Xenopoulos, M.A., 2009. Effects of agricultural land use on the composition of fluvial dissolved organic matter. Nat. Geosci. 2, 37-41. https://oi.org/10.1038/ngeo391

Wünsch, U.J., Murphy, K.R., Stedmon, C.A., 2017. The one-sample PARAFAC approach reveals molecular size distributions of fluorescent components in dissolved organic matter. Environ. Sci. Technol. 51, 11900-11908. https://doi.org/10.1021/acs.est.7b03260

Wünsch, U.J., Murphy, K.R., Stedmon, C.A., 2015. Fluorescence Quantum Yields of Natural Organic 
Matter and Organic Compounds: Implications for the Fluorescence-based Interpretation of Organic Matter Composition. Front. Mar. Sci. 2, 1-15. https://doi.org/10.3389/fmars.2015.00098

Wünsch, U.J., Stedmon, C.A., Tranvik, L.J., Guillemette, F., 2018. Unraveling the size-dependent optical properties of dissolved organic matter. Limnol. Oceanogr. 63, 588-601. https//doi.org/10.1002/lno.10651 
Table 1: Average extraction efficiencies of PARAFAC components. Standard deviations are provided to indicate ranges. "*, indicates that given extraction efficiency was calculated between components with low spectral congruence.

\begin{tabular}{lrc}
\hline Component & $\begin{array}{r}\text { Mean Extraction } \\
\text { efficiency }\end{array}$ & $\begin{array}{r}\text { Mean bulk extraction } \\
\text { efficiency at } \mathbf{F}_{\text {max }}\end{array}$ \\
\hline $\mathrm{C}_{330} *$ & $0.45 \pm 0.15$ & $0.40 \pm 0.12$ \\
$\mathrm{C}_{350}$ & $0.58 \pm 0.18$ & $0.40 \pm 0.10$ \\
$\mathrm{C}_{410}$ & $0.50 \pm 0.15$ & $0.40 \pm 0.07$ \\
$\mathrm{C}_{420}$ & $0.37 \pm 0.16$ & $0.43 \pm 0.08$ \\
$\mathrm{C}_{440} *$ & $0.33 \pm 0.07$ & $0.39 \pm 0.75$ \\
$\mathrm{C}_{500} *$ & $0.17 \pm 0.04$ & $0.32 \pm 0.09$ \\
\hline
\end{tabular}



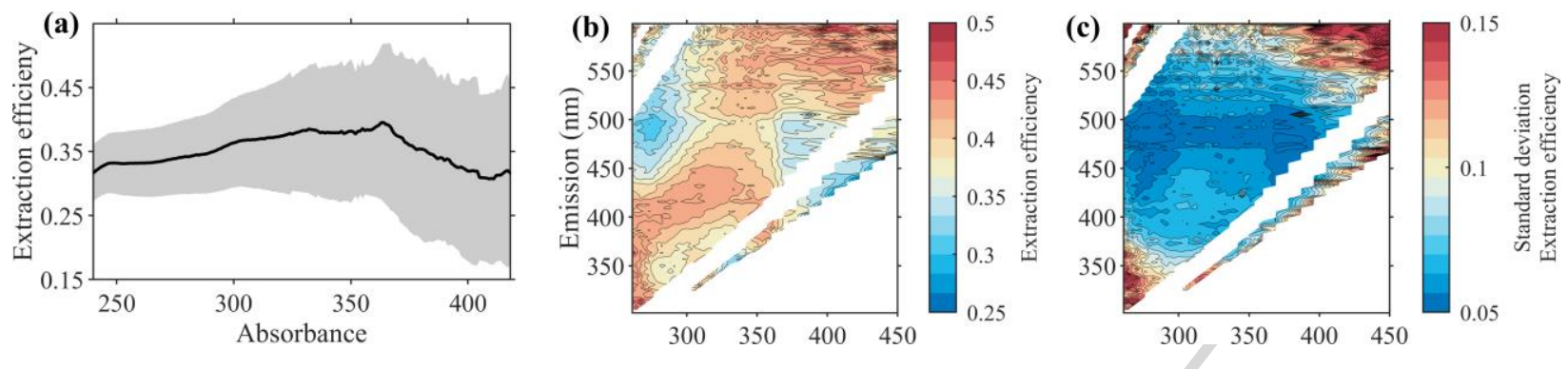

Figure 1: Extraction efficiencies of CDOM and FDOM. (a) shows average extraction efficiencies of CDOM as a function of absorbance wavelength (gray area shows standard deviation). (b) shows the average FDOM extraction efficiency and (c) shows the standard deviation of extraction efficiencies. CDOM extraction efficiencies are only shown for wavelengths $<418 \mathrm{~nm}$ since more than $50 \%$ of values were below the limit of detection above $418 \mathrm{~nm}$. 

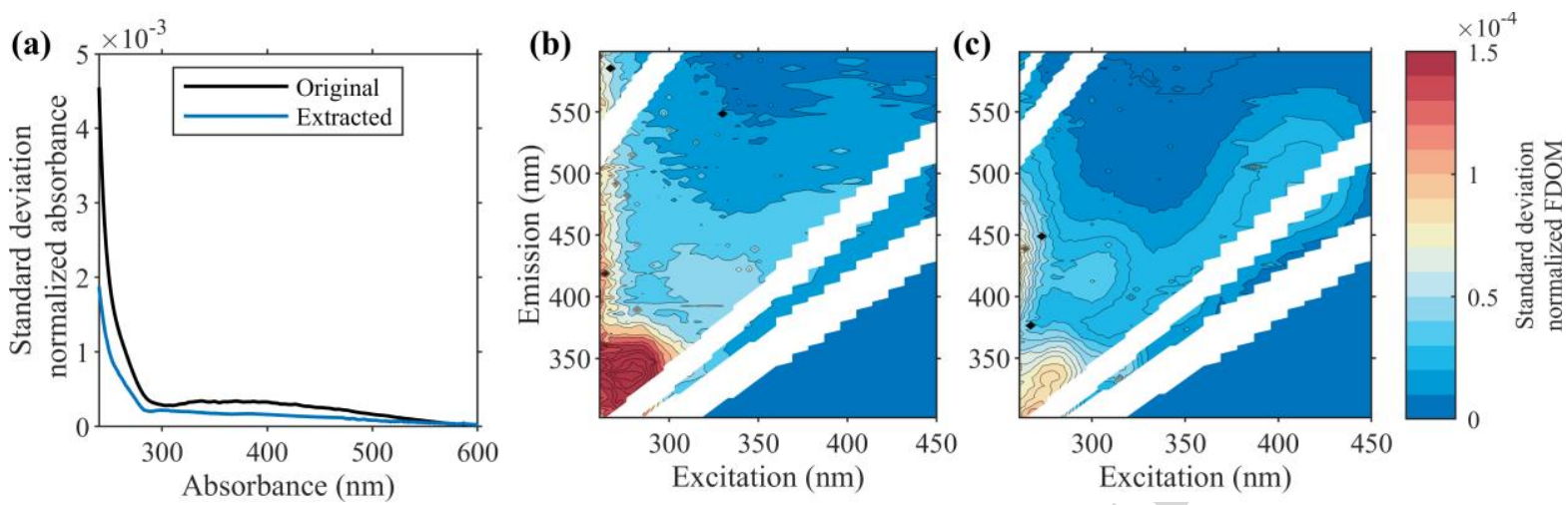

Figure 2: Spectral variability of CDOM and FDOM. (a) shows the spectral variability of original CDOM (black line) and extracted CDOM (blue line). (b) and (c) show the qualitative variability of original and extracted FDOM, respectively. All CDOM and FDOM spectra were normalized by their integral to facilitate the qualitative comparison. Color scales in (b) and (c) are equal to facilitate direct comparison of variabilities. 

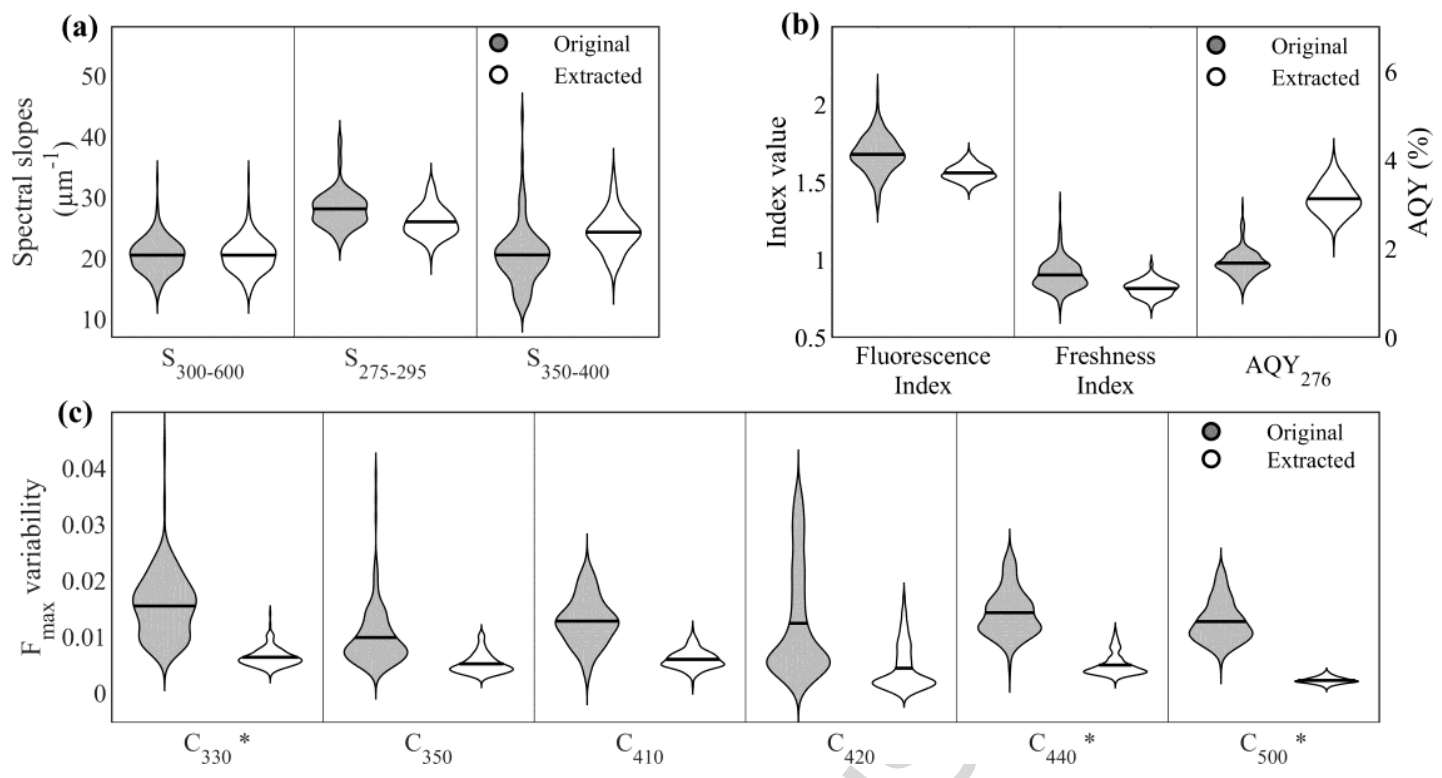

Figure 3: Comparison of optical properties between original and extracted CDOM (a) and FDOM (b-c). FI: FDOM fluorescence index; FrI: FDOM freshness index. CDOMSpectral fits (a) were restricted to $\mathbf{R}^{2}>0.99$. This restriction resulted in 188, 197, and 70 comparable samples for spectral slopes for $S_{300-600}, S_{275-295}$, and $S_{350-400}$, respectively. Average values are shown as horizontal, solid, black line. In (c), the * denotes comparisons between components with Tucker congruence values $<0.95$. 

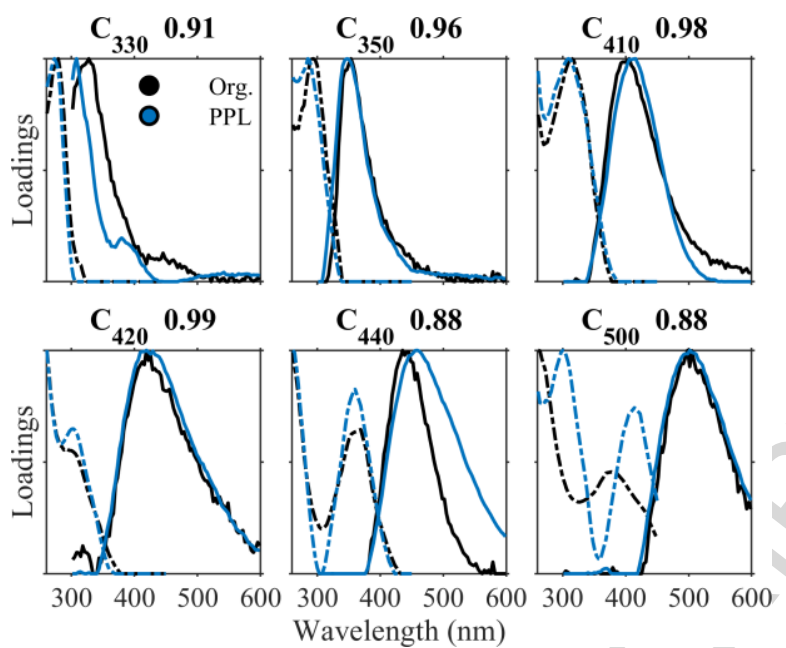

Figure 4: Comparison of six-component PARAFAC models fit independently to original (black lines) and extracted (blue lines) DOM samples. Spectral congruence coefficients are shown above each plot. Excitation spectra are shown as dashed lines and emission spectra as solid lines. 


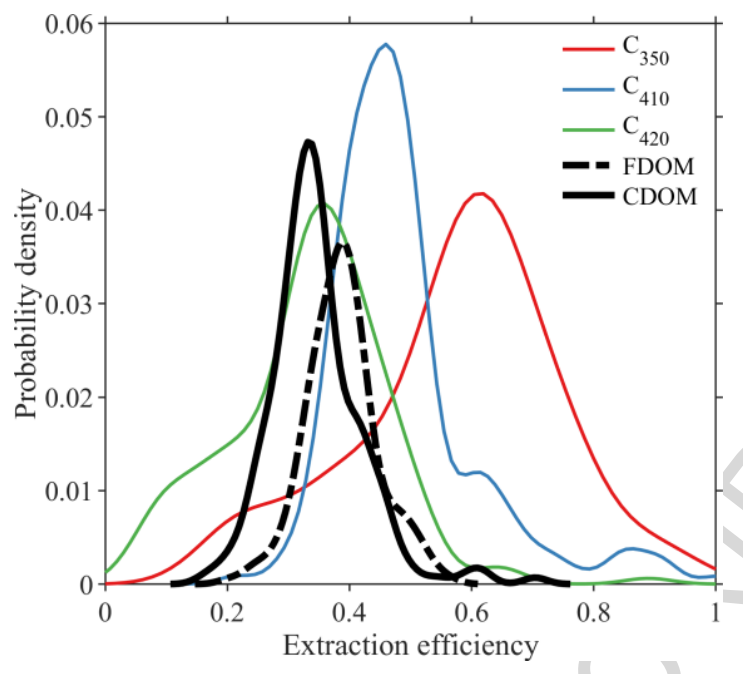

Figure 5: PARAF AC component extraction efficiencies. For reference, bulk CDOM and FDOM extraction efficiencies are plotted in black lines. Distributions for PARAFAC components with Tucker congruence $<0.95$ are not shown. 


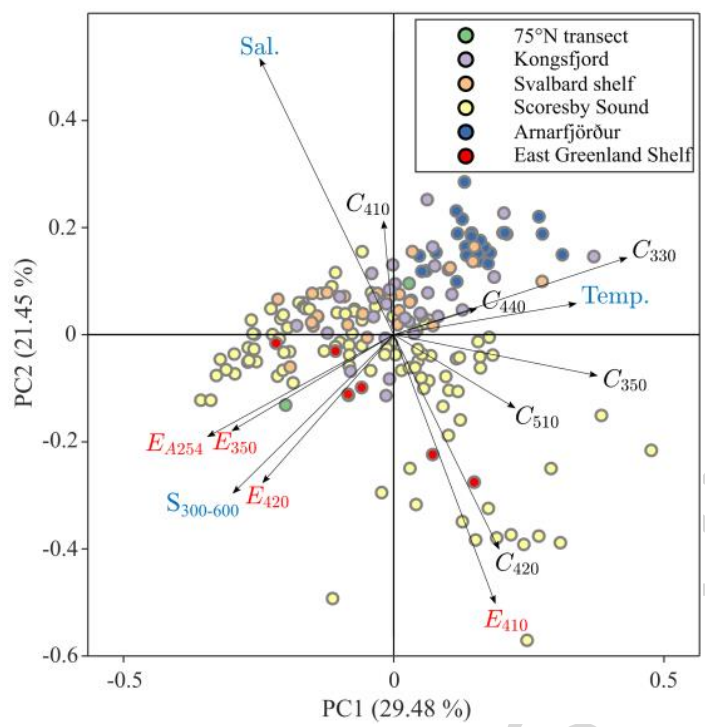

Figure 6: Principal Component Analysis biplot of extraction efficiencies and biogeochemical parameters. Scores are shown as dots and colored according to sample location (see Figure S1 for station locations). Loadings of extraction efficiencies are colored red (named e.g. $\mathbf{E}_{410}$ ), relative PARAFAC $\mathbf{F}_{\max }$-values are black, and temperature ("Temp."), salinity ("Sal."), and spectral slope $\left(S_{300-600}\right)$ are blue. Extraction efficiencies of $C_{330}, C_{440}$, and $C_{500}$ were not included in the analysis due to low spectral congruence between bulk water samples and extracted DOM.

Graphical abstract

Highlights:

- Solid-phase extraction occured at spectrally-variable recoveries for CDOM and FDOM

- Extraction changed widely-used fluorescence indicies and CDOM slopes

- Three of the six whole-water fluorescence components changed upon extraction

- Unchanged FDOM components were extracted with efficiencies between 37 and $58 \%$

- Extracts did not accurately reflect changes of most optical properties in bulk samples 